\title{
La escuela, un lugar para la apropiación de las prácticas corporales urbanas de danza en la Comuna 13 de la ciudad de Medellín, Colombia*
}

The school as a place for the empowerment of the urban corporal practices of dancing in the Commune 13 in the city of Medellin (Colombia)

\author{
Escola, um lugar para a apropriação de práticas urbanas corporais de dança na \\ Comuna 13 de Medellín, Colômbia
}

\begin{abstract}
Astrid Hincapié Zapata
Maestranda en Motricidad y Desarrollo Humano, Universidad de Antioquia. Miembro del grupo de investigación Prácticas Corporales, Sociedad, Educación-Currículo PES, ashinza23@yahoo.es
\end{abstract}

\section{RESUMEN}

Este artículo es un producto asociado a la investigación "La apropiación de las prácticas corporales urbanas de danza en la juventud de la ciudad de Medellín - Comuna 13", que se desarrolla en la maestría en Motricidad y Desarrollo Humano de la Universidad de Antioquia; se interesa por el hip hop como una práctica corporal urbana vivenciada y apropiada por los escolares, que disputan un lugar con el profesorado por la visibilización de ella como forma identitaria de los escolares. Los componentes de la práctica corporal a través de sus grafitis, música $(D j)$, canto (lírica, rap) y danza (breakdance) dejan leer una manera de pensar, consentir o resistir la realidad social. La práctica corporal llega a la escuela de forma soterrada en los actos libres del estudiantado o en los actos culturales institucionales. Esta etnografía escolar es orientada por la pregunta: ¿Cuál es el sentido del hip hop como práctica corporal escolar? La pesquisa aquí narrada surge en la escuela como una manera de comprender la etno-corporalidad juvenil en Medellín.

Palabras clave: etno-corporalidad, hip hop, buenas prácticas, educación corporal, escuela.

\begin{abstract}
This article is related to a research study on "The empowerment of urban corporal practices of dancing among young people in the city of Medellin - Commune 13" which is held by the Motor Function and Human Development Master Program from the University of Antioquia. The aim of this research is to use the Hip Hop as a living urban corporal practice that students empower showing their teachers that this practices are part of their identity. Graffiti, music (DJ's), singing (lyrics and rap) and dancing (breakdance) make part of these practices which show a way of living, agreeing or bearing students' acts or in the institution cultural activities. The question that guides this school ethnography is the following: Which is the sense of Hip hop as a school corporal practice? This issue emerges in school as a form of understanding the ethno-corporality of young people in the city of Medellin.
\end{abstract}

Key words: action, motor functions, didactics, relationality.

* Este artículo fue solicitado por la Revista Estudios Pedagógicos en diciembre del 2011 en el contexto del proyecto de Investigación FONDECYT (Fondo de Investigación Científica y Tecnológica) N N $^{\circ} 1110016$, titulado "Educación Física y su función de transformación de las desigualdades sociales: profesorado del área y documentación ministerial”. El artículo fue aceptado en junio de 2012. 


\section{RESUMO}

Relaciona-se à investigação "A apropriação de práticas corporais urbanas de dança juvenil de Medellín-Comuna 13", a qual desenvolve-se no Mestrado em Motricidade e Desenvolvimento Humano da Universidade de Antioquia; interessa-se pelo hip hop como prática corporal urbana de estudantes que o vivenciam e dele se apropriam como meio de dar visibilidade às próprias identidades. Os participantes da prática corporal, por meio de grafites, música (DJ), música (letra, rap) e dança (breakdance), permitem a leitura de um modo de pensar, consentir a realidade social ou a ela resistir. Tal prática chega à escola de forma encoberta nos atos livres dos estudantes ou nos atos culturais e institucionais. A questão, Qual é o sentido do hip hop como uma prática corporal escolar?, orienta esta pesquisa etnográfica que surge na escola como uma forma de compreender a etnocorporalidade juvenil em Medellín.

Palavras chave: etnocorporalidade, hip hop, práticas saudáveis, eduação corporal, escola.

\section{INTRODUCCIÓN}

La Comuna 13 está ubicada en el centro occidente de la ciudad de Medellín (Colombia); comprende 19 barrios (urbanos y semiurbanos) y su población se dedica en gran parte a actividades de comercio informal y, en menor porción, a las de tipo agropecuario; cuenta con un sistema integrado de transporte (Metro y Metrocable). Esta comuna ha sido el centro de situaciones de violencia, desplazamiento, mercado ilegal, entre otros; en razón de ello, demanda de la administración municipal y nacional la intervención del gobierno con planes que atiendan las condiciones sociales. Operaciones militares (Otoño, Contrafuego, Mariscal, Potestad, Antorcha y Orión en el 2002 , bases militares), educativas (plan desarme, policía juvenil, DARE), deportivas (INDER Medellín: escuelas populares del deporte, estilos de vida saludable) y culturales (pantalla de agua, parques biblioteca, conciertos, festivales, redes y asociaciones juveniles, abuelos cuenta cuentos) intentan dar respuesta a las problemáticas del contexto. En medio de la situación, aquí es posible identificar en los jóvenes un entramado de prácticas corporales urbanas entre las que se encuentran: las deportivas tradicionales, alternativas, extremas, ludo-deportivas barriales, tecnológicas y artísticas, que parecen representar una forma de expresar resistencia (Reguillo, 2000), consentimiento y autoafirmación, de vivir nuevas experiencias en las que se propicia una participación activa en el contexto local; esta emergencia configura identidades y formas de apropiar espacios en la ciudad.

Es posible evidenciar en la comuna 13 que las prácticas corporales urbanas de danza toman fuerza a través de ritmos como el reggaeton, la paipa, el tecktonic (electrónica) y el hip hop o la fusión de éstos con la salsa, el merengue o el tango; de todos ello, el hip hop y el reggaeton configuran con mayor definición, según Garcés (2005:139), la música como territorio. Los espacios configuran una geografía grupal, la pertenencia, el sentido otorgado por quienes interactúan en el lugar poblado por la música, el ritmo y el movimiento hip hop, definiendo identidades. Los jóvenes por medio del hip hop asumen formas lúdicas de vivir la corporalidad, socializarse, expresar ideologías, creencias, estilos de vestir, pensar, ser, en medio de la pérdida o reconfiguración de nuevas identidades en los

1 Operativos militares del año 2002 en la ciudad de Medellín - Comuna 13 realizados por el Ejército, la Policía Nacional de Colombia, el Departamento Administrativo de Seguridad (DAS), la Fiscalía, las Fuerzas Aéreas de Colombia (FAC) y las Autodefensas Unidas de Colombia (AUC), para acabar con la presencia generada por grupos de milicias urbanas de las Fuerzas Armadas Revolucionarias de Colombia (FARC), el Ejército de Liberación Nacional (ELN) y los Comandos Armados del Pueblo (CAP), con el propósito de "recuperar" la Comuna. 
barrios, ya sea por la presencia de grupos insurgentes, desplazados, o por otras situaciones que operan dentro y fuera de su contexto. Estos ritmos son lugares de expresión juvenil que los visibiliza en la ciudad; asimismo, como expresa el Mocho² (2010), estos ritmos aparecen en las escuelas de hip hop como estrategia para "extraer jóvenes del conflicto social". El hip hop también aparece como posibilidad de interacción entre grupos sociales, sirve de estrategia para la contención social, propósitos institucionales que se concretan en conciertos con consignas de no violencia, la promoción de los grupos con consignas de paz (conspirando por la paz), mensajes radiales y televisivos (sana convivencia y deber ser del ciudadano) que conviven con esfuerzos barriales reflejados en la destinación de recursos del presupuesto participativo, ${ }^{3}$ con la esperanza de que la práctica ofrezca un tiempo positivo para los jóvenes. La apropiación de la calle, el parque biblioteca, la esquina, son el margen de escape a la realidad de un sector de la ciudad en conflicto.

Por medio de la cultura hip hop, la juventud integra elementos de la cultura global, constituyendo identidades híbridas (con componentes musicales, rasgos corporales), expresiones reflejadas en el graffiti de la escuela y de la ciudad como medio de resistencia juvenil; sus líricas (letras de canciones) enuncian frustraciones, deseos, proyecciones, realidad del drama juvenil y la "ciudad oficial" molesta; "las batallas" ya no se vivencian desde las balas sino desde la música, el canto y la danza. De esa manera, la juventud se apropia de los espacios de la escuela y de la ciudad por medio del hip hop. La llegada de las prácticas corporales urbanas a la escuela se hace bajo situaciones circunstanciales, en las que el acto cívico, la jornada cultural o deportiva, fechas de celebración, requieren de grupos de baile tradicional, artístico, contemporáneo, que diviertan durante el espectáculo. En este sentido, la escuela resiste las situaciones propias del entorno juvenil y, por ello, pocas veces interconecta sus prácticas y conceptos con la realidad escolar; se desconocen las culturas juveniles emergentes en el contexto de ciudad, lectura que posibilita el reconocimiento de una etnocorporalidad juvenil. Este estudio centrado en estas prácticas, que se observan como un fenómeno social fuerte, asciende desde los años 80 y se distribuye en el espacio urbano a fuerza de práctica, a pesar de la violencia, debido a lo cual la población constituye una cultura corporal juvenil con códigos, espacios y tiempos diferenciables que no escapa a la escuela.

Al reconocerse el fortalecimiento de la práctica del hip hop en la ciudad, la investigación social la significa y la interviene desde el punto de vista del investigador. Esta investigación, en cambio, da sentido a la apropiación juvenil a partir de la voz de los propios actores -la juventud. Este estudio aporta desde la etnografía escolar, discursos y prácticas de aproximadamente tres mil jóvenes escolarizados y no escolarizados de la comuna 13 de la ciudad de Medellín. Otro aspecto relevante es la ocupación y apropiación de espacios en la ciudad que la juventud hace desde y a través de las prácticas corporales urbanas. Las fronteras reales e invisibles ${ }^{4}$ operan en la ciudad entre la calle y la escuela, entre comunas

2 Expresión de un Hopper de la agrupación Laberinto para la Revista Nación Subterránea (2010, publicación exclusiva).

3 Es un proceso abierto democrático que considera la opinión de la comunidad, quien define prioridades, decide proyectos, ejerce el control social del uso del dinero público y evalúa la gestión de sus gobernantes.

$4 \quad$ Zonas de los barrios o sectores de la ciudad que no pueden ser atravesadas por quienes no sean habitantes de los mismos, o quienes por ciertas situaciones sociales no pueden transitar porque es definido por un grupo armado. Ruiz (2003) las caracteriza como territorio que inicialmente es físico y que luego se configura como extensión vivida mentalmente, marcada y reconocida con códigos de representación colectiva. Quien traspasa 
y entre barrios, entre la cuadra y el barrio, entre los lugares oficiales e institucionales y los informales, por la pertenencia o asociación a grupos; barreras que llevan a ocupar e incluso a apropiar el parque biblioteca, la escuela, los parques de la ciudad, la calle, el garaje de la casa. Estas formas en que la juventud vive la escuela y ciudad se realizan por actos de consentimiento o de resistencia en la que el gobierno de la ciudad interviene con la institucionalización de programas a los que se articulan los diferentes grupos de danza urbana. De otra manera, la apropiación y ocupación genera luchas territoriales entre grupos y, al mismo tiempo, entre grupos y el gobierno; en caso contrario, el establecimiento de procesos de mediación entre los diferentes actores sociales trae consignas como: "Sin armas la vida es otro cuento", "Plan desarme" y "no existen fronteras invisibles".

La anterior problemática nos lleva a plantearnos una serie de interrogantes que parten de preguntas por el sentido del hip hop como práctica corporal escolar; ellas son: ¿Cuál es la apropiación de las prácticas corporales urbanas de danza que hace la juventud en la escuela? ¿Cuál es la apropiación espacio - temporal? ¿Cuáles son las que se instalan y resiste la escuela? ¿Cuáles son los rasgos identitarios que constituye la práctica? ¿Cuáles son las interacciones que se producen entre grupos escolares?

\section{CONCEPTOS DE PARTIDA PARA LA COMPRENSIÓN ETNOGRÁFICA}

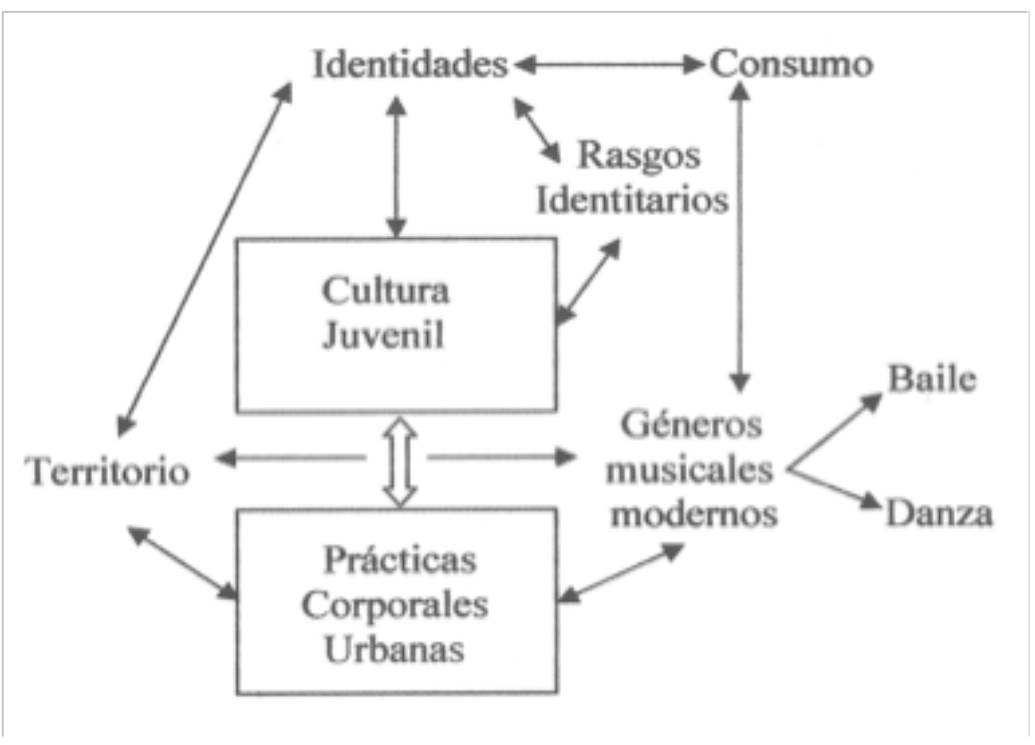

Esquema 1. Conceptos articuladores

estas fronteras puede ser víctima de los violentos. En Medellín en el año 2010, 12.000 estudiantes desertaron del sistema educativo formal a causa del conflicto armado o las fronteras invisibles.. 


\subsection{PRÁCTICAS CORPORALES}

Las prácticas corporales son ejecuciones corporales que se realizan con significados y propósitos propios. En ellas emergen expresiones biológicas, estéticas, emocionales, sociales, políticas y culturales. Estas prácticas se mueven entre lo formal y lo informal (Galvis, 2009), lo institucional y la apropiación de los espacios y territorios de ciudad, lo tradicional y lo contemporáneo; desde allí la juventud construye unas identidades regionales, individuales, musicales, de género, locales, deportivas, religiosas, entre otras. Según Cachorro (2009: 2), son expresiones o manifestaciones que, puestas en escena, "además de estar dotadas de complejos engranajes de las acciones motoras, ofrecen dimensiones que exceden la contemplación de la motricidad, están movidas por subjetividades peculiares, enhebran deseos, frustraciones, angustias, satisfacciones que permiten interpretar configuraciones particulares del movimiento".

Las prácticas corporales son movidas por los intereses y motivaciones propias de la juventud, así como por las necesidades y características de los contextos en las cuales emergen, las exigencias institucionales y la normatividad de los agentes educativos, religiosos, políticos y gubernamentales, así como por las apropiaciones espacio-temporales de los territorios de la ciudad. La juventud ejecuta esta serie de prácticas corporales en la ciudad y una ciudad, en términos de Martínez Bonafe (2009), es curriculum y no se puede vislumbrar sin pensar el sujeto que la habita, la interpreta, la vive o malvive. En este habitar de la ciudad, se despliegan unas prácticas corporales que cobran carácter de institucionalidad (escuela, programas de gobierno, secretaría de cultura) o que tienen carácter informal porque surgen en la calle, en la espontaneidad, aunque, en ocasiones, se fusionan o pasan a ser absorbidas por aquellas de carácter formal en la escuela.

\section{Prácticas Corporales Urbanas}

Las prácticas corporales urbanas son aquellas que se ponen en escena en la ciudad, emergen de las culturas juveniles y se muestran como una manifestación política, social, que permite mostrar una resistencia, unos rasgos identitarios particulares y una posibilidad de expresión y apropiación de los espacios de ciudad. Las prácticas corporales urbanas o de ciudad se inscriben "en los procesos de mundialización de las culturas" (Cachorro y Díaz, 2004: 62), influyendo sobre la educación corporal de los ciudadanos del siglo XXI, ya acostumbrados a ver propuestas corporales de distintos países para ir modelando un "nuevo sensorium" que altera las motricidades.

En la cultura corporal existen distintas formas de vivir el amplio espectro de propuestas corporales disponibles, diversas prácticas que se despliegan en la ciudad y que son denominadas para esta investigación prácticas corporales urbanas. 


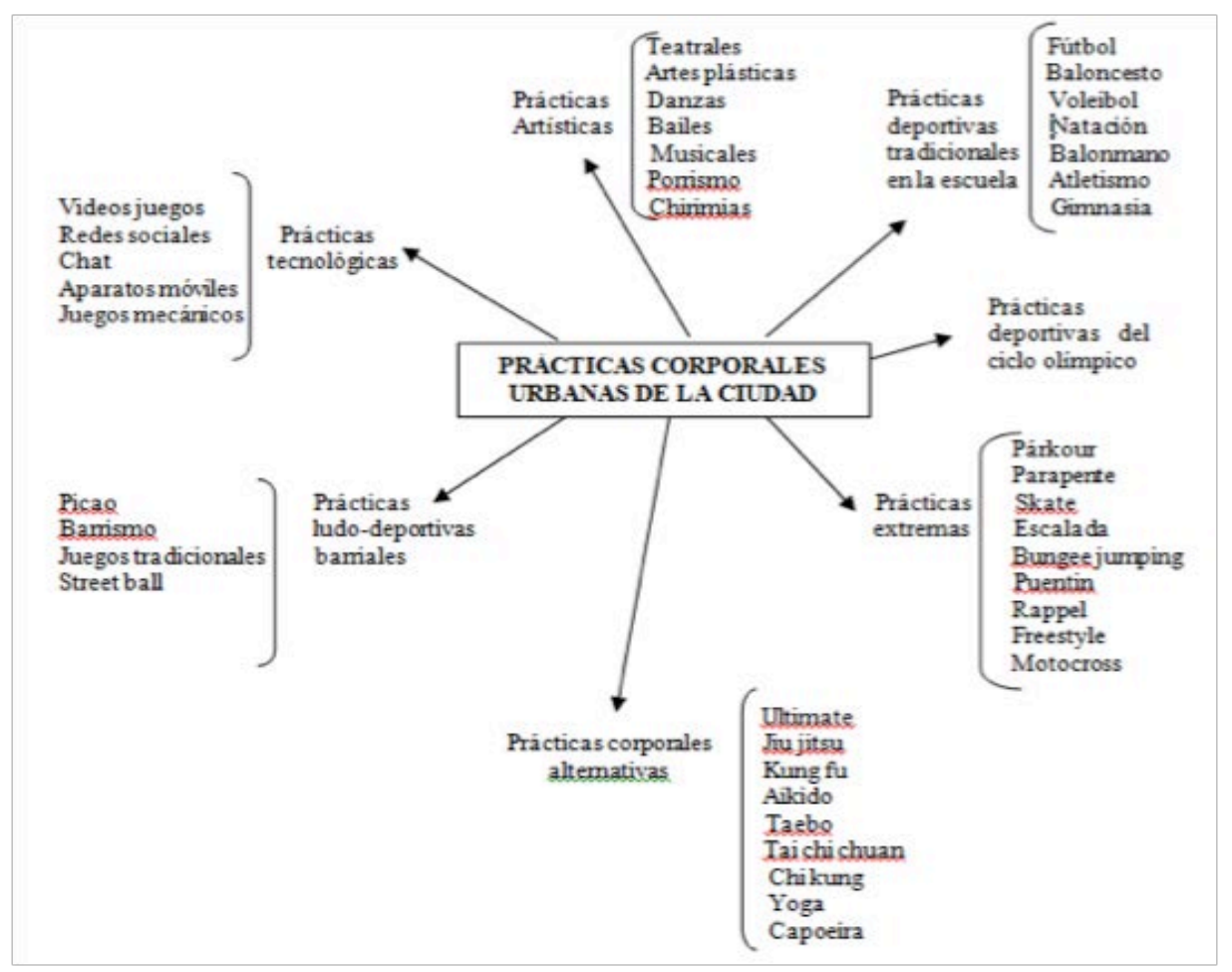

Esquema 2. Prácticas Corporales Urbanas

Frente a las prácticas corporales urbanas de danza y baile, hay que proponer una distinción que hacen diversos autores dado su sentido. En cuanto a la danza, Hanna (1979: 19) la plantea como "secuencia de movimientos corporales, no verbales con patrones determinados por las culturas, que tienen un propósito y que son intencionalmente rítmicos con un valor estético a los ojos de quienes la presencian”. Al respecto, Le Boulch (1997:130), Barysknikov (Cit. en Gardner, 1991: 87) refieren que la danza es una expresión espontánea y natural en el ser humano utilizada como forma de comunicación e, incluso, de aquellos sentimientos que resultan difíciles de verbalizar. En tanto, Londoño (1995) alude al baile como movimiento rítmico espontáneo de lo que transmite la música (deseos); es el ritmo el que marca el movimiento, mientras en la danza la melodía y el ritmo marcan códigos culturales. En ambas, el uso genera diversión social o actividad de recreación, pero la transmisión de valores estéticos y éticos, propósitos educacionales y conocimiento de culturas son asignados específicamente a la danza.

En la comuna 13 de la ciudad de Medellín, es posible encontrar en la cultura de los hoppers que el breakdance constituye una práctica corporal urbana de danza en la que confluye la expresión, el dominio de una técnica, la indumentaria, la manifestación de una cultura juvenil, una expresión del pensamiento y una forma de percibir el mundo y la realidad. Este ritmo musical, a diferencia de otros, da cuenta de una resistencia 
social, mientras que otros, tales como el reggaeton, la paipa y la electrónica (tecktonic) son estilos juveniles que, en términos de Garcés (2005), no reflejan una ideología, sino que responden a un movimiento de globalización, consumo y moda.

\subsection{CULTURAS JUVENILES}

Del predominio de una sola cultura (pensamiento moderno) se tiende a la emergencia de culturas en lo que hoy se denomina aldea globalizada (pensamiento posmoderno). El surgimiento de microculturas o microsociedades es equivalente a lo que Silva refiere como nuevas sociedades primitivas. Zarzuri (Cit. en Silva, 2002) expresa que el mapa urbano es alterado con el surgimiento de nuevas sociedades en las metrópolis y su emergencia se debe, en el fondo, al intento de destruir (la variedad cultural) que reconstruye o recrea nuevas formas de culturas y, como bien él lo indica, con intenciones a resistir o contestar a una cultura dominante. En este sentido, la juventud emerge de manera intuitiva o sistemática a las grandes corrientes hegemónicas, buscando "rehacer aquellos lazos rotos o perdidos, producto de los fenómenos mundiales de modernización, y lo hace desde lo que mejor conoce: una vuelta a lo tribal, en el sentido de una mayor incidencia de lo emocional-afectivo, aquello que es propio de la comunidad de hermanos, de los que comparten un destino y una finalidad común" (Silva, 2002: 121).

Según Maffesoli (1990), hay una nueva tendencia, un nuevo tipo de agrupamiento, unas "tribus" que han cubierto el mapa humano de las grandes urbes y, por supuesto, el de los medios de comunicación, quienes amplían ese fenómeno y son su principal sostén. Garcés (2005: 40), en este sentido, plantea que los "jóvenes agrupados y fuertemente diferenciados por mecanismos de identidad, logran ser colectivos y, por tanto, trascienden búsquedas individuales o efímeras; esas culturas quizás alcancen una participación socio-política, dependiendo de su nivel de organización para la acción colectiva, su fortalecimiento grupal y la proyección de sus propuestas"; a estos grupos definidos con intereses comunes es lo que llamamos culturas juveniles. Los grupos de jóvenes, además de compartir un estilo juvenil (objetos emblemáticos, vestuario, género musical), tienen encuentros ideológicos que les permiten asumir una posición social.

Es importante resaltar que en dichas culturas se encuentran jóvenes homogéneos y diferenciados, en los cuales existe una compleja red identitaria que los agrupa y desagrupa, consiguiendo crear un estilo propio que les permite "identificarse con los iguales y diferenciarse de los otros" (Reguillo, 2000: 28). En el caso de los hoppers en la ciudad de Medellín, se trata de una postura frente a la visibilización y construcción de una ciudad más pacífica, conservando un estilo de vida propio articulado por el grupo al que pertenecen, en el que "el vestuario, la música, el acceso a objetos emblemáticos, constituyen una de las importantes mediaciones" (Reguillo, 2000: 27) para su constitución identitaria, aunque este estilo es distinto al de los jóvenes que se articulan a los mercados de consumo (caso de los reggaetoneros, quienes al parecer carecen de una ideología propia fundamentada, con posicionamientos sociales propios, y más bien responden a consumos musicales y estéticos a partir de los que construyen su propio estilo juvenil). 


\section{Identidades}

Al interior de una cultura juvenil se dan procesos de constitución identitaria por medio de la búsqueda y afirmación de su propio yo. Inicialmente, existe una partida del seno familiar para emprender la búsqueda de grupos de referencia; el encuentro ya no es en los parientes, está por fuera de ellos, con los del barrio, escuela, club deportivo, otros que pueden ser amigos o no. La salida, como lo plantea Silva (2002:123), se encuentra "a la caza de elementos y rostros que les dé una identidad, es decir una seguridad mínima sobre la cual armar su propia visión de lo que son y lo que desean ser". La construcción o reconfiguración identitaria se produce en el proceso de reconocimiento con otro u otros: son construcciones que se definen en la interacción de iguales.

Los procesos de constitución de la identidad personal que tiene la juventud, son reconfigurados en la constitución de identidades sociales en la búsqueda del reconocimiento e, incluso, del estigma. Los pares o iguales cobran relevancia por los rasgos que allí se definen, a saber, códigos corporales estéticos y sociales que asignan la definición o emergencia de una tribu. Aguirre y Rodríguez (1996) plantean que "la identidad tribal se organiza en torno a unas coordenadas de espacio y tiempo, dentro de las cuales los miembros del grupo: manifiestan y desarrollan una cultura propia y diferencial lenguaje, símbolos, rituales y ceremonias", en la que la referencia de iguales es la clave sin desconocer las diferencias (Barbero, 2002; Garcés 2005; Salerno y Silba, 2006; Silva, 2002; García, 1992).

Los rasgos identitarios siempre van a estar mediados por la cultura, la cual deja consigo marcas simbólicas que cada grupo social le asigna, respondiendo a valores culturales. En este proceso de constitución identitaria se consolida, además, lo que ha sido denominado identidad femenina/masculina, por la cual el o la joven pasan a pensar, actuar y sentir como hombre o mujer a partir de instancias simbólicas, representaciones, afectos y comportamientos culturales. De esta manera, en la cultura hopper se observa una "exaltación del cuerpo masculino, en tanto la territorialidad musical del hip hop está en relación con los espacios de la calle y el barrio en extenso; espacios vedados a la mujer, de quien se espera que permanezca en los lugares dispuestos para la intimidad, la maternidad, el cuidado de la familia" (Garcés, 2005: 49). En general en las culturas juveniles, la mujer parece invisible, quizás respondiendo a la tradición de que la mujer debe permanecer recluida en el hogar o a la normativa que plantea la necesidad de que esté ausente de las calles, lugar donde la juventud consolida rasgos identitarios. Es así como en la cultura hip hop, según Garcés (2005), la mujer aparece pasiva, marginada.

\subsection{TERRITORIO: OCUPACIÓN - APROPIACIÓN DE ESPACIO}

Las maneras en que ocupamos el espacio y hacemos territorio están directamente relacionadas con las representaciones de nosotros mismos en el mundo. Los sujetos, las familias y los grupos no habitan los barrios solamente por el uso que pueden hacer de ellos, sino porque también son signos de prestigio, de distinción, de clasificación social.

No existe identidad, vínculo e historia que no se concretice e inscriba en un tiempo y en un espacio. Al narrar la propia historia, ésta se inscribe en un espacio que se ha vuelto un lugar. El lugar está vinculado con la idea de identidad y de sentido simbolizado. La identidad barrial se relaciona con el poder de habitar. "Las culturas juveniles urbanas se 
van configurando como espacios de identidad de socialización de jóvenes para jóvenes y se fortalecen con el debilitamiento de los mecanismos de integración tradicional (escuela, familia, trabajo, religión) y el descrédito de las instituciones políticas" (Garcés, 2005: 78).

La ocupación y apropiación ${ }^{5}$ de los espacios a partir de la música en la ciudad de Medellín, se evidencia en espacios no institucionalizados como son la calle, el parque, la esquina, la cancha, el garaje, el parque biblioteca, en donde la música es el territorio, puesto que ella, como lo expresa Garcés (2005: 79), "guarda y contiene los referentes simbólicos que les permite a los jóvenes agruparse y diferenciarse". Por tanto, el espacio público posibilita "la configuración de territorios juveniles, los cuales se entienden como espacios de socialización e identidad de jóvenes y para jóvenes" (Ibíd).

Según Márquez (2008), hablar de identidad también significa hablar de territorialidad por ser un rasgo compartido por todos los sujetos sociales. Cuando las narrativas identitarias de estos pequeños territorios urbanos denominados barrios no son reconocidos o son negados, ellos pierden su carácter de espacio intersticial, de puente entre el mundo privado y el público, entre el hogar y la ciudad, transformándose así en la trampa identitaria del ghetto. O, en el caso del hip hop como territorio juvenil, poblado de recuerdos, olvidos, vida cotidiana, barrio, calle, como plantea Garcés (2005:79), quien ha estudiado los territorios de violencia urbana, destacando "una relación entre vivencia y lugar que constituye el territorio", lugar de emociones y experiencias barriales.

La calle se constituye en el sentido de las culturas juveniles marcada por la memoria de las experiencias grupales, los momentos de encuentro, fiesta, ritual juvenil. Para la cultura hopper, como lo expresa Garcés (2005: 82) en su investigación, la calle "es la escuela de la vida", en ella se canta, se baila break dance, se pinta graffitis, se produce música. Las culturas juveniles no seleccionan la casa, la escuela y la iglesia como lugares de encuentro dado que éstos son propios de los adultos, es decir, espacios de socialización tradicional. Reafirma la misma autora que con el hecho de habitar y socializar en otros espacios, se consolidan los territorios juveniles; por medio de éstos se constituyen las identidades, una producción cultural propia alejada de la homogenización de los adultos y, por tanto, la apropiación de unos espacios no institucionalizados, en donde la calle, la esquina, el parque se constituyen en lugares de significados regidos por sus propias normas y dominio.

\section{METODOLOGÍA}

Esta investigación encuentra en la lógica cualitativa, a través del enfoque etnográfico, un medio adecuado para la comprensión de las prácticas corporales urbanas de danza realizadas por la juventud de Medellín. Se opta por este enfoque porque permite una inmersión intensiva al interior del grupo social que se quiere estudiar con la intención de efectuar una documentación, descripción y comprensión de una etnocorporalidad juvenil

5 Los conceptos de ocupación, apropiación e invasión se encuentran asociados y refieren a la propiedad sobre el espacio. La ocupación es asumida por los sujetos como un acto de restablecimiento de un derecho; se ocupa un espacio porque se considera que se tiene derecho sobre él: tener una casa digna, por ejemplo. No obstante, en la visión de quien la posee y siente vulnerado su espacio esto se puede calificar de invasión. La apropiación sugiere una relación donde el espacio es la manera en que son organizados los individuos y programadas las acciones sociales que se despliegan dentro de sus coordenadas (Lefebvre, 1970). 
en la escuela. Así, esta investigación privilegia la emergencia de categorías Emic, es decir, la descripción desde el punto de vista del "nativo", como lo propone Rockwell (2009), intentanto "documentar lo no documentado" en voz de la juventud de la Comuna 13.

En calidad de "docente investigadora", ${ }^{6}$ se observan y registran eventos, conciertos, escenarios naturales (calle, parque, escuela) en los que se llevan a cabo las prácticas. Dada esta condición, el extrañamiento (ver diferente lo que es cotidiano) es una característica que acompaña la observación participante. El significado de la cultura (Aguirre, 1995) es tejido con los hoppers, los escolares, la juventud. Y a la par que se inicia la estructuración del asunto de investigación, se realiza un desplazamiento por la ciudad en el cual se participa de diversos conciertos organizados por la Alcaldía de Medellín y el Presupuesto Participativo dirigidos a la niñez y la juventud de la ciudad, eventos de corte gratuito, espacios en los que se toman registros fotográficos y fílmicos, se graban discursos y consignas, se contactan agrupaciones artísticas. La observación también se realiza en la escuela en diferentes momentos: clases (educación física, artística, ética, lengua castellana), descansos, actos cívicos y culturales, entrada y salida de la escuela, jornadas extraescolares deportivas y culturales.

Por medio de la fotoetnografía, la investigadora y los "nativos" realizan tomas fotográficas y fílmicas de sus prácticas corporales; son ellos quienes obturan y centran el foco del registro. En la escuela, poco a poco, la cámara y la filmadora se evidencian como una herramienta más del proceso educativo, familiarizándose con éste y actuando espontáneamente en las diferentes situaciones escolares y extraescolares. Resulta agradable la manipulación de este tipo de tecnología y se disputan la utilización del mismo para aportar al proceso investigativo. Pese a las características sociales y de conflicto en esta zona, que hacen difícil fotografiar ciertas situaciones, la colaboración de los jóvenes en la escuela y en los distintos sectores de la ciudad son claves en este proceso. Otro elemento clave y alternativo son los registros compartidos en las redes sociales de las cuales participan los jóvenes, consiguiendo así acceder a la información requerida.

El etnodrama entendido por Weisz (1994) como el drama de la etnia, es aquél que representa por medio del juego dramático el rito, la fiesta, la danza, la ceremonia con fines investigativos. El etnodrama en esta investigación lo constituyen momentos en torno a la construcción de murales realizados por los estudiantes en las clases, talleres y conversatorios alrededor de éstos, los discoforos y cineforos desarrollados con temáticas relacionadas con el asunto investigativo, las producciones textuales con temas específicos, los dibujos alrededor de las prácticas corporales urbanas de danza. Este tipo de técnica permite ampliar la caracterización de las prácticas, reconociendo los sentidos y significados que éstas representan en la juventud de la ciudad y, al mismo tiempo, ampliando la mirada que, por las situaciones propias del conflicto social y por cuestiones de seguridad de los informantes y la investigadora, limitan la toma fotográfica.

La fotoetnografía, el etnodrama y la observación participante son registrados en fotografías, videos y diario de campo, instrumentos para acceder a la cultura investigada. La información recolectada es tratada a través del análisis iconográfico (descripción investigados e investigador) inspirado en la práctica de Létourneau (2007): categorización

6 Educadora de Básica Primaria de una Institución Educativa de la Comuna 13, quien se encuentra inmersa en el campo tomando registro de lo observado y distanciándose de la cultura con el objeto de comprenderla. 
abierta y flexible y ampliación del foco de documentación referenciada y no referenciada para triangular y construir el relato etnográfico.

\section{RESULTADOS}

Existe tensión entre las prácticas corporales tradicionales con las prácticas corporales de danza (hip hop - reggaeton). El desarrollo de las prácticas corporales en la escuela es espejo de las prácticas corporales urbanas, sin embargo, las de hip hop y reggaeton son vetadas por la corporalidad que produce desde el pensamiento adulto.

Pese a que la escuela niega las prácticas corporales urbanas de danza y baile, los jóvenes en actos de resistencia las hacen visibles en las propuestas culturales y cívicas. La entrada soterrada de la práctica es de permanente lucha entre el profesorado y los jóvenes escolares.

Se identifica el acumulado corporal producto de estas prácticas corporales, es decir, una etnocorporalidad juvenil que conforma identidades juveniles, una cultura corporal que expresa rasgos conformativos evidentes en la manera de vestir, bailar, rapear, pensar, sentir.

En la comprensión de la práctica corporal del hip hop en la escuela se encuentra un margen para el pensamiento juvenil, la espontaneidad, con la que se desarrolla la presión social en la que viven los jóvenes habitantes de Comuna 13. Así, algunos encuentran en la práctica una salida al conflicto escolar, barrial.

La interacción que posibilitan las prácticas corporales urbanas, especialmente la de hip hop, cambia la relación del territorio; la juventud desterritorializa la escuela y el barrio con la apropiación de estas prácticas.

Se reconoce la práctica del hip hop como una práctica corporal contemporánea en la que tienen cabida los iguales, para el caso de los hombres y mujeres, así pertenezcan a una misma generación. Ellos libran una batalla entre lo femenino y lo masculino, prevaleciendo el pensamiento adulto tradicional frente al referente de lo que es la mujer.

\section{DISCUSIÓN}

5.1. TENSIÓN ENTRE LAS PRÁCTICAS CORPORALES TRADICIONALES CON LAS PRÁCTICAS CORPORALES DE DANZA. EL HIP HOP BROTA POR LOS POROS

$$
\begin{array}{r}
\text { ¡No basta educar al cuerpo para la } \\
\text { salud y la higiene sin "recrearlo", sin distenderlo, } \\
\text { sin asociar el ejercicio físico al placer! } \\
\text { Soares (2006) }
\end{array}
$$

En la escuela existe un espectro de prácticas corporales tradicionales que han estado presentes para la reproducción (Giroux, 1985) de cuerpos que respondan a parámetros establecidos institucionalmente, lo que genera, en palabras de José Ignacio Barbero (2002), una cultura corporal hegemónica. La escuela escolariza el cuerpo (Calvo, 2005), manteniendo en su selección curricular una educación del cuerpo con trazas de uniformidad representadas en el vestuario, las filas, el corte del cabello, los accesorios, las expresiones, la higiene, los contenidos de la clase de Educación Física, etc. Esto, en términos de 
Rosa (2005, Cit. en Soares, 2006: 11) "son construcciones realizadas por influencia del pensamiento eclesiástico para el establecimiento de una moral social, dictando buenas costumbres y conductas".

En el curriculum de la escuela -Comuna 13- se han privilegiado los deportes tradicionales como la gimnasia, el baloncesto, el fútbol, el voleibol y el atletismo desde un enfoque militar para el entrenamiento y regulación de los mismos. De esta forma, la clase de educación física ha desplegado series repetitivas de ejercicios cronometrados y repetitivos hasta alcanzar unos parámetros requeridos para aprobar el área. La juventud introduce en la escuela un entramado de prácticas corporales urbanas de danza, vedadas por la escuela y que rescatan el concepto de disfrute, expresión y emoción propia de éstas. Dichas prácticas rompen con el concepto de homogenización de los cuerpos, "la visión mecánica de gesto humano, en que todo debe ser precisamente codificado, geometrizado y sus resultados calculados" (Soares, 2006: 19).

En la escuela escenario de esta investigación, se encuentra en tensión una serie de prácticas corporales urbanas, las cuales se ubican entre lo tradicional, lo ludo deportivo barrial y lo dancístico. El fútbol se vive tanto en la escuela como en el barrio y representa para la juventud una oportunidad de figurar y salir de pobres. El picao $^{7}$ y los juegos tradicionales de la calle son un margen por fuera de la clase de Educación Física, momentos aprovechados en el recreo y, además, permitidos por las directivas y docentes para el esparcimiento y la diversión.
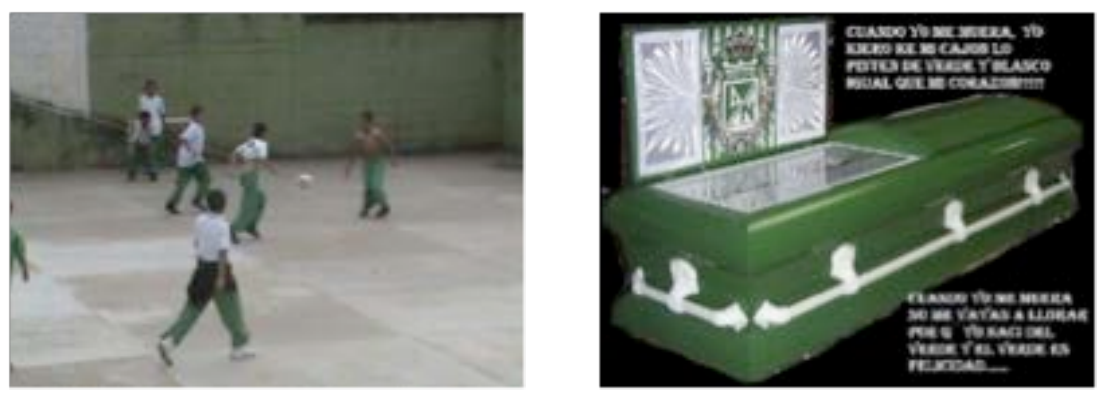

En las fotografías se encuentran estudiantes de grado $5^{\circ}$ jugando un partido de microfútbol en jornada extraescolar. La pasión por el verde (Club deportivo Atlético Nacional, equipo de la ciudad) es símbolo en la escuela. Las prácticas corporales conllevan rasgos característicos que se reflejan en el espacio escolar, vehículo de cómo se vive dentro y fuera del estadio -muchas veces, por ejemplo, el patio escolar es batalla de hinchas-. En dicho escenario, participan de esta práctica corporal niños, jóvenes y adultos, quienes en la clase de educación física, el descanso, las tardes libres o los fines de semana solicitan el lugar y, poco a poco, ciertos grupos han ocupado y hoy apropiado el espacio escolar para esta práctica.

Al ingresar a la escuela el día lunes, los estudiantes solicitan el balón de microfútbol para jugar un partido; les digo que no es posible porque los arcos están completamente dañados. Ante esto, uno

$7 \quad$ Partido de microfútbol callejero. 
de los estudiantes responde que ya hay arcos nuevos, que el día de ayer los trajeron; al observar la cancha, efectivamente los encuentro y los estudiantes afirman: los "muchachos del hueco que juegan aquí en la escuela con nosotros todos los domingos los trajeron y están mucho más finos que los otros, éstos si van a durar mucho más profe, están bien buenos”. Pregunto: ¿Quiénes son esos muchachos? y ellos responden: pues los "muchachos", profe. Indago al coordinador por los arcos nuevos y encuentro que ni siquiera tenía conocimiento de éstos, pero una de las profes responde que hace muchos años estos muchachos han venido a jugar a la escuela los domingos, que ha sido una práctica de años" (DC escuela, Agosto 2011).

Esto da cuenta de la importancia que tiene la práctica corporal del fútbol en la comuna (pero también en la ciudad), y cómo los escenarios de la escuela sirve de encuentro para diversos grupos juveniles. Podríamos hablar así de una desterritorialización, ya que en ella participan y se encuentran sujetos de diversos sectores de la comuna que afuera no pueden interactuar pero dentro confluyen pacíficamente. El uso que adquieren ciertos espacios de la Comuna 13 y la forma cómo se mueven entre las denominadas fronteras invisibles, es también una condición de la escuela, al ser ocupada por un grupo armado mientras ellos juegan su partido. La escuela se define como territorio de insurgentes, en tanto los jóvenes escolares la desterritorializan con sus prácticas, así afuera la guerra continúe.
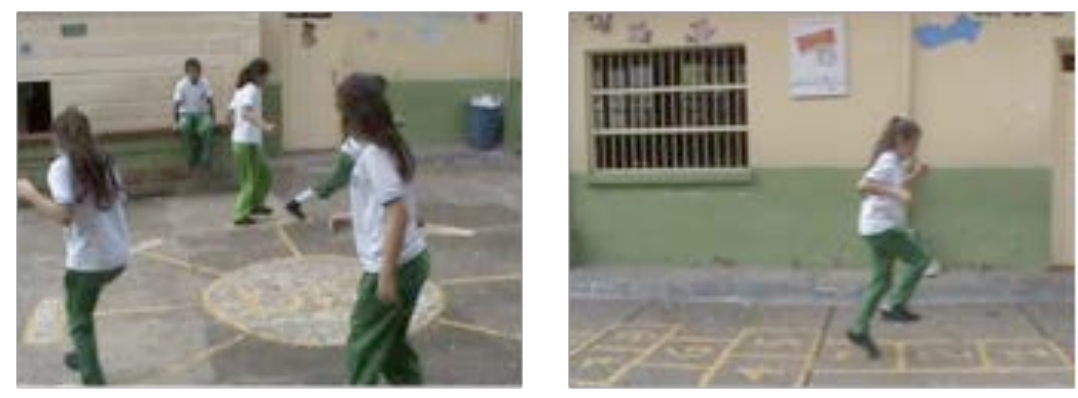

Otras prácticas que toman forma en la escuela, son los juegos tradicionales de la calle. Arriba, a la izquierda, se observan 5 estudiantes participando del stop, el cual consiste en girar hasta que se dice la palabra stop y luego se inicia una batalla de países que se desarrolla como un juego de persecución. Arriba, a la derecha, se encuentra una estudiante saltando golosa, juego que ha sido tradicional en la ciudad de Medellín y no sólo en la Comuna 13. Estas prácticas han entrado en disputa con las de danza y baile urbano; se juega, pero se reclama: queremos música, déjennos bailar.

Los relatos de una mayoría de jóvenes dan cuenta de su añoranza por la música que les es cotidiana. Uno de ellos expresa: "El personero nos prometió música en el recreo y no nos cumple, todos son iguales, sólo es de campaña"; ellos juegan, pero el reclamo es permanente ante la negativa del hip hop, el reggaeton, la electrónica y la paipa, ritmos preferidos por ellos, en especial el último, característico de los habitantes de Comuna 13. Tanto grandes (grado $5^{\circ}$ ) hasta chicos (preescolar), expresan espontáneamente los ritmos, cantan, rapean, bailan, al punto de que algunos docentes expresan que eso lo llevan en la sangre. Se identifica entre los jóvenes una habilidad para bailar asociada a quienes son llamados "inquietos". El estigma pesa sobre quienes bailan, "ustedes no 
estudian pero para bailar ahí sî’, comentarios de profesores que ven en sus practicantes un rótulo de indisciplina; el control es no música, no baile. La regulación corporal es mediada por las prácticas corporales urbanas de danza y baile, premio o castigo. Muchos jóvenes se preguntan por qué no está la música en la escuela, antes era permitido y ven una esperanza en la promesa de su personero.

El reclamo de la juventud escolar transciende las palabras, las actividades en la escuela posibilitan expresiones como los murales en los que se identifica su pensamiento. ¿Pero cuál es el sentido que ellos atribuyen a sus murales y qué representan? En los murales se establece una relación directa con el graffiti de la ciudad; éste, junto a otros elementos como rapeo, DJ y breakdance componen la práctica del hip hop. En esta investigación, por medio del desarrollo de los murales con temas libres, se logra captar el pensamiento de los escolares, en los que parece ser superada la moda de hip hop para ser parte de su identidad corporal. Los rasgos identitarios se hacen visibles en la escuela, pues la uniformidad es quebrada con la expresión de sus dibujos en el mural. Frente a esta actividad, los estudiantes refieren:

se pueden expresar nuestras ideas porque la gente puede ver lo que uno quiere en la ciudad, se pueden expresar muchas cosas, uno puede escribir lo que quiera, lo que siente (Comentarios de estudiantes de $5^{\circ}$ ).

Los estudiantes conciben el mural como un todo con un estilo artístico aplicado a las paredes o muros de la ciudad o del barrio, en el cual aparece el graffiti como un elemento constituyente de la cultura hip hop, el que permite expresar una idea o sentimiento por medio de letras gruesas, entrelazadas, de colores diversos y elaboradas con vinilos o aerosoles sobre telas que decoran paredes o que dan una identidad particular a un puente, escuela, esquina, canchas, coliseo.

A continuación se da cuenta a través del ejercicio fotoetnográfico y la lectura iconográfica lo que representa para los investigados y la investigadora el trabajo sobre el mural. La fotografía, su descripción, la voz de los jóvenes escolares, la de la investigadora, la emergencia de categorías y focos que amplían la lectura sobre la observación y permiten la construcción de la narrativa.

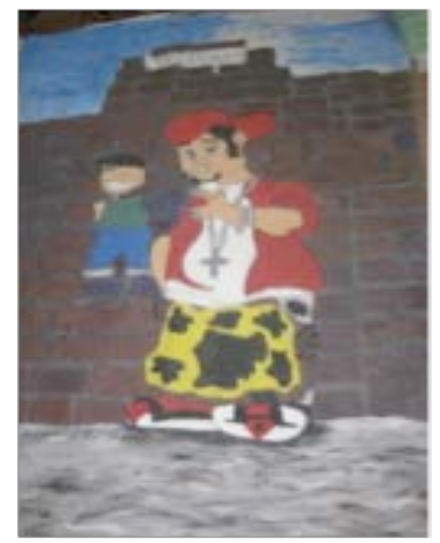

Fotografía de Esquema 3. B 24 MURALES 


\begin{tabular}{|c|c|c|c|c|}
\hline DESCRIPCIÓN & VOZ DEL NATIVO & $\begin{array}{c}\text { VOZ DE LA } \\
\text { INVESTIGADORA }\end{array}$ & $\begin{array}{l}\text { CATEGORÍAS } \\
\text { EMERGENTES }\end{array}$ & $\begin{array}{c}\text { REFERENTES } \\
\text { CONCEPTUALES }\end{array}$ \\
\hline 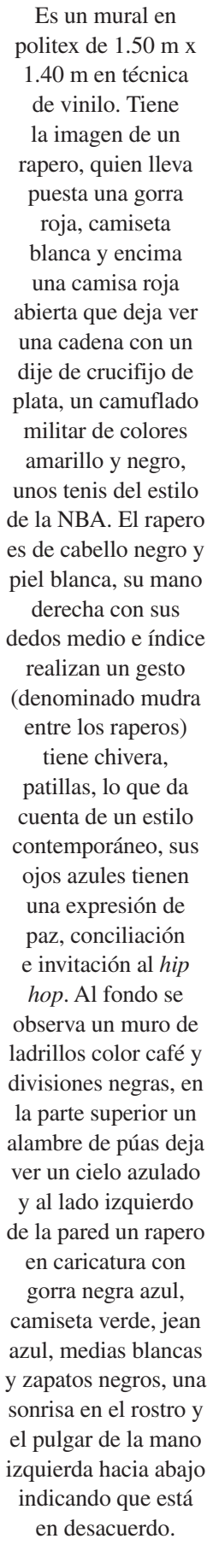 & 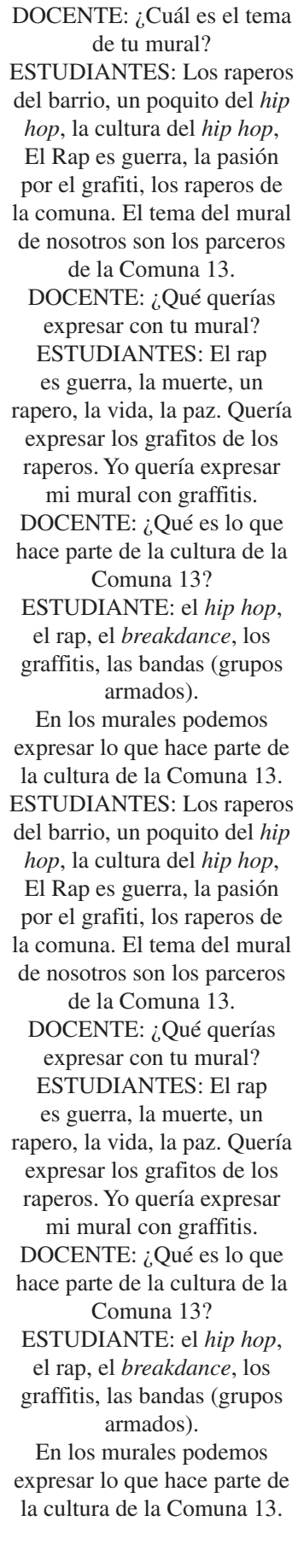 & 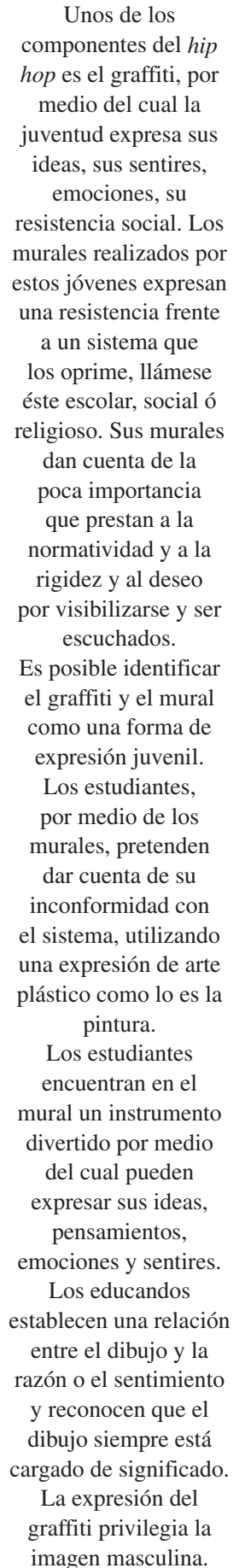 & $\begin{array}{c}\text { Rasgos } \\
\text { identitarios } \\
\text { Cultura hip hop } \\
\text { Pensamiento } \\
\text { escolar } \\
\text { La } \\
\text { curricularización } \\
\text { de las prácticas } \\
\text { corporales } \\
\text { barriales }\end{array}$ & $\begin{array}{c}\text { Cultura corporal } \\
\text { y vida cotidiana } \\
\text { (Barbero, 2006) } \\
\text { Entre nos-otros } \\
\text { (Garcés, 2005) } \\
\text { El currículum en la } \\
\text { ciudad y la ciudad } \\
\text { en el currículum } \\
\text { (Martínez, 2009) } \\
\text { La prácticas } \\
\text { formales e } \\
\text { informales } \\
\text { (Galvis, 2009) }\end{array}$ \\
\hline
\end{tabular}


Los graffitis, entonces, son un instrumento que tiene gran significación y sentido para la juventud de la ciudad, se convierten en una marca personal para quien los realiza, permiten expresar emociones, sentimientos, ideologías, resistencia, lo que les da reconocimiento; a través de los dibujos y mensajes plasmados en éstos, es posible entrever la realidad de la juventud (el conflicto, la drogadicción, el narcotráfico, la guerra, la vivencia en el barrio), la representación del mundo, el deseo por vivir en un lugar más tranquilo y, además, su preferencia por el género musical urbano (hip hop). También se describen los lugares que caracterizan la Comuna 13, los lugares que ocupan y apropian con las prácticas. Expresiones como las que a continuación se describen dan cuenta de sus intereses:

"profe es que yo quiero hacer un dibujo bien tierno" "yo quiero que mi dibujo sea de violencia" "¿cómo hago para hacer un dibujo de guerra, de violencia?” "iprofe puedo hacer un dibujo de un rapero? (Comentarios de estudiantes de $5^{\circ}$ durante el trabajo de los murales).

Por medio del análisis iconográfico se encuentra que los estudiantes, a través de sus murales, evidencian rasgos de identidades híbridas, las cuales se entretejen entre lo regional (ideologías o formas de pensamiento de cubano, africano, estadounidense), lo estético, lo corporal, lo filosófico y lo globalizado a través de lo que les llega por los medios masivos de comunicación (Dragon Ball Z, Winnie Pooh, J Balbin, Piolín, Mi pequeño Pony, Daddy Yankee, Agrupación Aldeanos, Nach), los cuales se convierten en un ícono corporal para ellos. De igual forma, se encuentra que el rapero, para la juventud, representa un joven que tiene convicciones, lucha por sus ideales y se puede expresar libremente por medio de su canto, danza, música y graffitis. Para otros, el mural es el deseo de vivir en un mundo más pacífico, donde se respeten los derechos y se pueda convivir en armonía, experimentando la alegría, la solidaridad, la valentía, el respeto, la ternura y el amor.
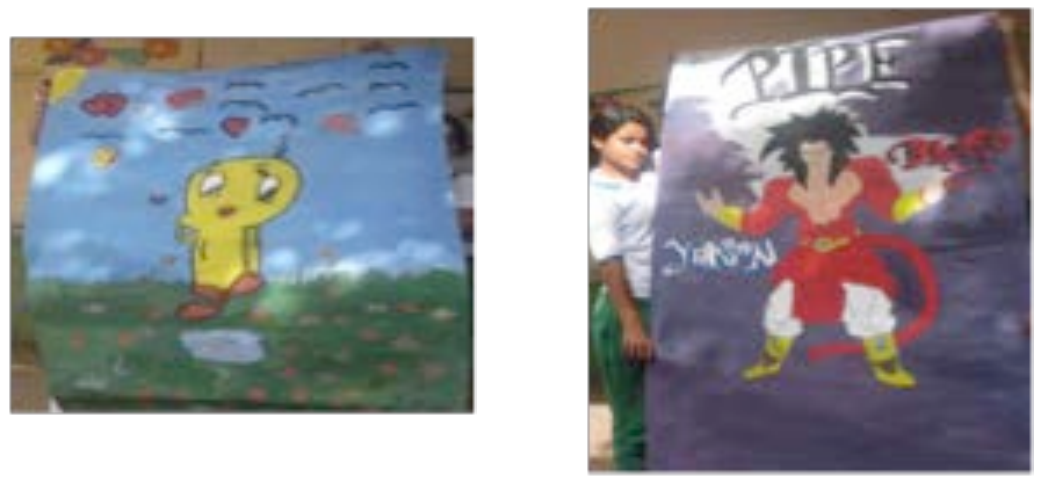


\subsection{EL ETNODRAMA, UNA MANERA DE COMPRENDER LA ETNO-CORPORALIDAD JUVENIL}

La juventud en sus prácticas corporales escolares da cuenta de su realidad y cotidianidad. El etnodrama representa para esta investigación una manera de hacer visible la realidad contextual de los estudiantes, con el fin de identificar las características, expresiones y sentidos de las prácticas corporales urbanas que emergen como situación de resistencia en la Comuna 13. El etnodrama permite hacer una lectura del conflicto social en el cual están inmersos los jóvenes de la ciudad, la manera cómo se agrupan los jóvenes para darse una lucha por un territorio que les permita acceder a un mercado ilegal de armas, droga, municiones, mujeres, prostitución, sicariato, muerte y secuestro de jóvenes en la zona, o la apropiación de un territorio musical que les posibilite expresarse libremente y atraer a la juventud por medio del arte fuera del conflicto, así otros mueran por cantarlo. En fin, la configuración de una identidad juvenil a partir de un bombardeo de situaciones, en las cuales los jóvenes están llamados a tomar decisiones, a asumir posturas que requieren una fuerte configuración de su personalidad, ética y valores.

Por medio del etnodrama, los escolares consiguen expresar sus vivencias cotidianas, lo cual resulta complejo por la crueldad, el temor, la inseguridad que esto representa para ellos. En pocas palabras, presentar sus propias situaciones o las del barrio o comuna, significa exponer su propia vida y una muestra clara de ello son las estadísticas de los raperos muertos en la ciudad ${ }^{8}$ o los jóvenes víctimas del conflicto social o protagonistas del mismo. Contar sus propias historias de vida o su realidad por medio del juego teatral con fines investigativos, escribir, dibujar y conversar sobre ello, les brinda la posibilidad de abrirse interiormente para dar a conocer todos aquellos elementos propios de la cultura juvenil, con la tranquilidad de no exponer su vida y de reservar la información y a sus informantes.
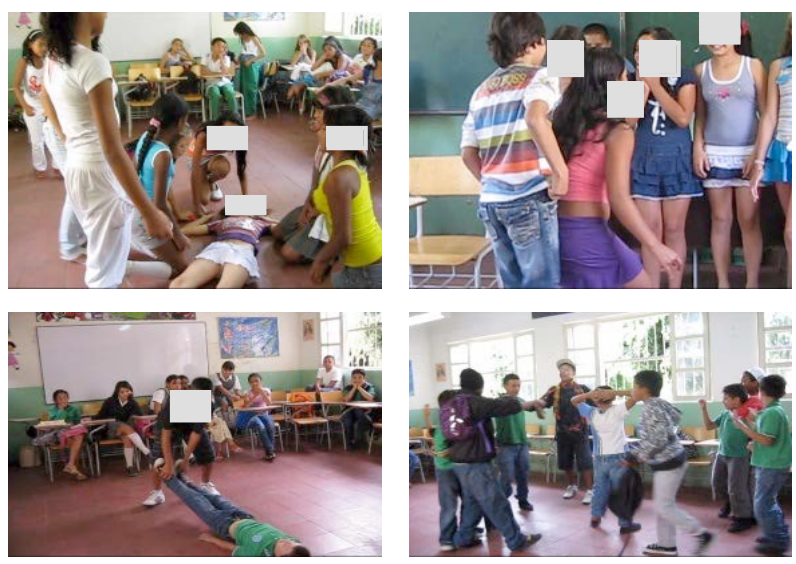

8 En los últimos tres años los medios de comunicación anuncian la muerte de nueve artistas en la ciudad de Medellín. 
En el conjunto de fotografías visible más arriba, la imagen de la izquierda superior muestra a las estudiantes representando la muerte reciente de una joven (hermana de una estudiante), que fue baleada por uno de los combos del barrio tras estar implicada en el secuestro de una amiga a causa de un chisme relacionado con la prostitución, reconstituyendo el levantamiento del cuerpo después de llamar a la fiscalía. En la fotografía de la derecha superior, se representa un burdel en el que dos policías vestidos de civil, entran y capturan a unas jóvenes dedicadas a la prostitución; una de ellas se está rayando ${ }^{9}$ con un joven. En la fotografía de la izquierda inferior, se representa un baleo entre dos combos de la zona (Comuna 13 - Corazón), en el que muere un joven y el que lleva puesto un "mocho" (pantalón corto) lo arrastra para tirarlo por un despeñadero. En la fotografía de la derecha inferior, se muestra el enfrentamiento de dos combos en el que hay un estudiante en el centro a quien llevan capturado.

Estas imágenes muestran la manera cómo los estudiantes viven y reflexionan sobre la violencia que se vive en las calles y esquinas de la comuna 13, el conflicto armado y las incidencias que tiene el pertenecer o no a él, por sus múltiples formas de morir en búsqueda de dinero a través del sicariato, los grupos armados (conformación, reclutamiento), la prostitución o las balas perdidas. El miedo, el susto y la muerte son una constante en la Comuna 13; hacen parte de la cotidianidad de los estudiantes, tal cual lo expresan, viven una realidad de zozobra, a la expectativa de quienes sobrevivirán el instante siguiente. Por medio del etnodrama es posible reconocer el pensamiento, el mundo interno de los jóvenes de este contexto; a ellos les atrae el suspenso, puesto que forma parte de su realidad, hablan de fantasmas, espíritus, apariciones, observan películas de suspenso, terror (La llorona, Juegos macabros, Enterrados vivos, Silencio mortal), las cuales les atraen no sólo por el suspenso sino por el sufrimiento, el derramamiento de sangre, la maldad, la muerte; en éstas, los estudiantes ven reflejada la realidad de su contexto. Tales evidencias, que se manifiestan en sus dibujos y conversatorios, como sucedió en un discoforo sobre la canción de Aldeanos "El rap es guerra", permiten a los escolares plantean lo siguiente:

-Van a quitar la base militar...-iQué bueno! Esos policías que le tienen miedo a los pandilleros.-Profe, justed no conoce nada! Los charcos quedan arriba, arriba y más arriba es donde secuestran la gente, la entierran viva. Una vez llevaron una pareja, la desnudaron, los amarraron a un árbol y los dejaron morirse. Es que allá entierran la gente viva, eso está lleno de muertos, las personas desaparecidas es porque las matan y las tiran allá. ;Ay! Yo fui un día por allá y eso está lleno de mariposas, yo encontré allá "la cola" de mi papá cuando lo mataron, es que por allá le tiran los genitales a las personas o las partes como los dedos, las manos, los pies. No ve que a mi papá lo mataron y la policía dijo que era por quitarle la moto, pero eso era mentiras porque él quedó muerto con la moto al lado, pero lo bueno fue que los que lo mataron también los mataron a la otra semana y mataron a ese man y a la esposa, la mujer que estaba embarazada y le metieron un tiro al bebé en la cabeza (DC escuela, Marzo de 2011).

La juventud ha empezado a vivenciar el hip hop como una forma de resistirse a las prácticas de violencia y a la muerte que diariamente rodea sus vidas; en palabras del "Mocho", integrante de la agrupación Laberinto:

9 Expresión juvenil que significa rozar los genitales con otra persona mediante el baile. 
decidimos crear estas escuelas populares para robarle jóvenes al conflicto, para sacar de las esquinas y los jibariaderos a los jóvenes que de una u otra forma se sienten más atraídos por el hip hop, que por un bareto, que por un arma y que por estar en las vueltas [...] estamos dándole formación política a los pelaos en el barrio para que entiendan de sus derechos y puedan algún día frentear toda esta envestida que hay en este momento en las comunas" (Revista La Nación Subterránea, p. 15).

El análisis de la canción "El rap es guerra”, permite identificar cómo la juventud, por medio de las líricas, evidencia la resistencia expuesta con anterioridad sobre la violencia; aquí la guerra es vivenciada desde el verso, la rima, la música, el canto y la danza, por ello se habla de batallas de MC (competencias de raperos mediantes rimas libres y con temática), de breakdance (danza urbana), DJ (los productores de música) y competencias de graffiteros, los cuatro componentes del hip hop. Aldeanos, la agrupación autora de esta canción, muestra como el rap incentiva la resistencia social: "Luchar por un cambio social que no le conviene al gobierno/ Serás un problema interno/ Otro pueblo entre locos que te llamaran loco / (¡Sólo porque no estás mintiendo!) [...] Guarda el Nintendo aquí nadie regala vidas / El campo de batalla es la calle tu apoyo un puño arriba / No hay más salida buscas gloria erra / Si vas a entrar piénsatelo / (¡El Rap Es Guerra!) / Y en las filas de este escuadrón me alisto / Con el micrófono en la mano del silencio desisto / ¡Sé que me has visto...! Ametrallando a la mentira / Son balas mis palabras y no mi boca mi mente las tira [...] El rap es de guerra por eso en TV no sale".

En la canción interpretada por agrupaciones que sobresalen en la ciudad de Medellín "Conspirando por la paz", de igual manera se hace visible la resistencia por la violencia y el deseo de habitar en una ciudad más pacífica: "Por favor no me pregunte por la guerra / Pregúnteme por la paz / No quiero ir al cementerio / A visitar muchos más / Todo lo que hemos visto / Trae consecuencias / Ilusiones del barrio que narro con experiencias [...] Si quieres ser pacifico, Aprende a perdonar / Si quieres ser del combo, al amor hay que apostar / No nos tramas con tus armas, Con tus balas / Con la guerra que maltrata y diario nos mata [...] Mientras unos quieran dividir por fronteras la ciudad / Hoy el arte hace un enlace clase de solidaridad / De amabilidad fraternidad con alianzas / Voces que inspiran en contra de la guerra / sin perder las esperanzas [...] Sepultamos la violencia, la música nuestra arma / Paz en los corazones y en el mundo la calma" [...] (Canción interpretada por agrupaciones raperas de Medellín, 2011).

A partir de estas líricas es claramente visible que el rap es un medio de expresión juvenil y una práctica corporal que invita a la juventud a vivir en una ciudad más pacífica y tranquila, a luchar en contra de la guerra, a tomar conciencia de los efectos sociales que esta trae consigo, a acabar con las fronteras invisibles y, por tanto, los jóvenes han empezado a organizarse por medio de redes juveniles a través de las cuales enfrenta algunas problemáticas de la ciudad como lo es el conflicto armado.

Los escolares logran hacer lectura de la realidad que buscan los hoppers de la ciudad: unirse bajo una sola voz, con el propósito de transmitir por medio de sus versos un mismo mensaje, el ideal por una ciudad más pacífica, sin guerra, asumiendo el arte como un enlace que crea alianzas y que permite acabar con la división de los barrios a causa de las fronteras invisibles. De esta forma, los hoppers fundamentan su discurso en líderes reconocidos mundialmente como Rigoberta Menchú, Martin Luther King y Gandhi y su ideología de la paz del mundo, lo que da cuenta de un pensamiento social 
definido, del cual empiezan a apropiarse los estudiantes y que da cuenta, en términos de Garcés (2005), de una cultura juvenil.

\subsection{BATALLAR LO FEMENINO Y LO MASCULINO}

La representación del pensamiento femenino se encuentra impulsada por los medios masivos de comunicación, la globalización, las experiencias y creencias culturales. La mujer en la historia ha sido evidenciada por debajo del concepto masculino, lo cual ha generado la necesidad de irse dando un lugar en la historia, el cual, pese a que el tiempo y las épocas se transforman, no ha sido fácil y aún la mujer continúa buscando un posicionamiento más equitativo en la sociedad. La identidad femenina se ha ido transformando; ahora la mujer no es aquella que se doblega ante los hombres y se muestra como inferior. Desde que la mujer pudo acceder al mercado laboral transformó su mirada del mundo, su vestuario, la estética de su cuerpo. Ahora la mujer tiene una mirada altiva, es una mujer que exhibe su cuerpo.

Según Garcés (2005: 47), "las raíces de la masculinidad o la feminidad son pues el resultado de aprendizajes sociales que diferencian y asignan comportamientos muy específicos para cada género [...] La identidad femenina o masculina pasa por un actuar, pensar, sentir como hombre o como mujer a partir de instancias simbólicas, de representaciones, de afectos y comportamientos culturales".

Se define la masculinidad y la feminidad por Florence (1985: 60, Cit. en Garcés, 2005: 47) "como llena de valores, construidos a partir de representaciones, mitos, fantasmas, etc... de nuestra cultura". La mujer moderna se caracteriza por ingresar al mercado laboral, lo cual la incita a salir al mundo exterior y realizar otras actividades.
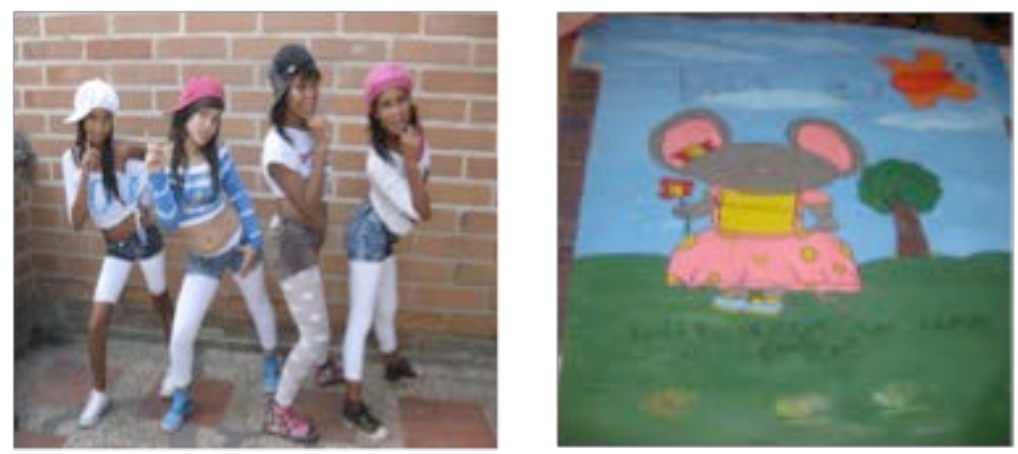
En esta investigación, las chicas se identifican desde la realización de los murales con un ideal de ciudad, de barrio más pacífico, respetuoso, tranquilo, ecológico (menos urbano), tierno, limpio, amoroso. Ello se ve evidenciado en los dibujos (animales tiernos, personajes de caricaturas o películas que representan estas situaciones: ratona con flores, Winnie Pooh llorando, Piolín pensativo...). Se evidencia una fe esperanzadora en los amigos como aquellos que te brindan su compañía, cariño, aprecio, consejo y ayuda.

En contraste con esto, las mujeres, por medio del etnodrama, dan cuenta de las situaciones de la realidad que las rodea: prostitución, muerte, drogadicción, maltrato, alcoholismo; consiguen traer situaciones de su cotidianidad, su contexto, y por otra parte, ponen en juego que no están en consonancia con esta realidad y que, por ello, desean y anhelan otro tipo de realidades, vivencia de valores, cese de la violencia y la guerra, tener una pareja que las respalde y las cuide; hay una preocupación por encontrar un amor ideal, un amor que no produzca sufrimiento y este deseo posiblemente surge de la realidad en la cual se encuentran inmersas, niñas, jóvenes provenientes de familias disfuncionales, en las que la figura del padre está ausente, las mujeres son maltratadas por sus esposos, los hijos provienen de diferentes padres, carece el alimento lo que conduce a las madres a ser cabeza de familia y a buscar alternativas (prostitución, nuevas o múltiples parejas). Hay un deseo por un amor que sea complementario, que respete y valore, dicho deseo va aunado al deseo por una familia. Esto se hace evidente en sus comentarios:

Profe ¿Es que usted no piensa en tener hijos? ¡Pero si eso es lo más importante! Todas las mujeres tienen que tener hijos (Comentarios de estudiantes, DC Julio 2011)

Hay un ideal por una mujer que se casa para conformar una familia, tener hijos y un esposo que los protege a todos. Dicho anhelo está dado por las vivencias históricas por las cuales ha atravesado la mujer que la han llevado a verse como aquélla que debe quedarse en casa, mientras el hombre es quien accede al mercado laboral y económico.

La dualidad de estas vidas femeninas/masculinas se corresponde con la oposición de espacios bien delimitados y diferenciados por el adentro (el hogar, la iglesia, el costurero) y el afuera (la calle, el café, la cantina, el taller lo cual delimita unos espacios de oposición para la mujer y para el hombre, desde adentro y afuera). Cada espacio modela un hombre y una mujer particulares, y si ellas traspasan las puertas del hogar para dirigirse a la calle, se entiende que abandonan la condición ideal de la mujer y su vida corre un incierto destino de perdición y pecado y si el hombre permanece en el hogar también será objeto de crítica y observación permanente, aunque no tan severo (Garcés, 2002: 144).

Este ideal cultural de la mujer se opone a la realidad; por un lado, está lo que desean, pero, por el otro, su comportamiento refleja una serie de conductas que muestran a una mujer luchadora, trabajadora, fuerte, que exige sus derechos y que se independiza económicamente del hombre.

Con relación al hip hop, se evidencia que hay "una exaltación del cuerpo masculino, en tanto la territorialidad musical del hip hop está en relación con los espacios de la calle y el barrio en extenso; espacios vedados a la mujer, de quien se espera que permanezca en los lugares dispuestos para la intimidad, la maternidad, el cuidado de la familia" (Garcés, 2005: 49).

La mujer ha tenido que irse abriendo un espacio el cual ha sido propio de los hombres, quienes, socio-históricamente, se han mostrado como los fuertes, quienes tienen el control y el poder de la norma, la autoridad, el trabajo. La mujer ha sido vista en 
tiempos anteriores como el sexo débil, aquélla que necesita cuidados, protección, que se destaca por sus movimientos suaves y delicados, por su expresión dulce y tierna, por ser emotiva. Dichas características no son propiamente las del hip hop, una cultura urbana que muestra resistencia, fuerza, desafío desde el baile, la danza, el canto, el dibujo y la música, características que hacen pensar en una mujer masculinizada, lo cual desde una perspectiva social ha lentificado su presencia en las culturas juveniles urbanas, pero que, dado el contexto de la posmodernidad, ha generado espacios para que explore otras alternativas, diversas prácticas corporales desde las cuales busca visibilizarse en una sociedad que las ha hecho invisibles.

En el caso del hip hop:

la imagen masculinizada del hopper se relaciona con contextos de violencia armada, donde la dimensión masculina tiene un protagonismo central. Esa imagen ha sido estereotipada por la publicidad y las industrias culturales, al poner en circulación en el mercado, ante todo, a hombres jóvenes rodeados de confort y consumo, acompañados de una mujer dispuesta al sexo; esa imagen invisibiliza el rol de la mujer en el mundo hopper. Sería necesario revisar la imagen de mujer hopper, que difunden los medios masivos de comunicación, pues generaliza un cuerpo femenino dispuesto para la sexualidad y el consumo" (Ibíd).

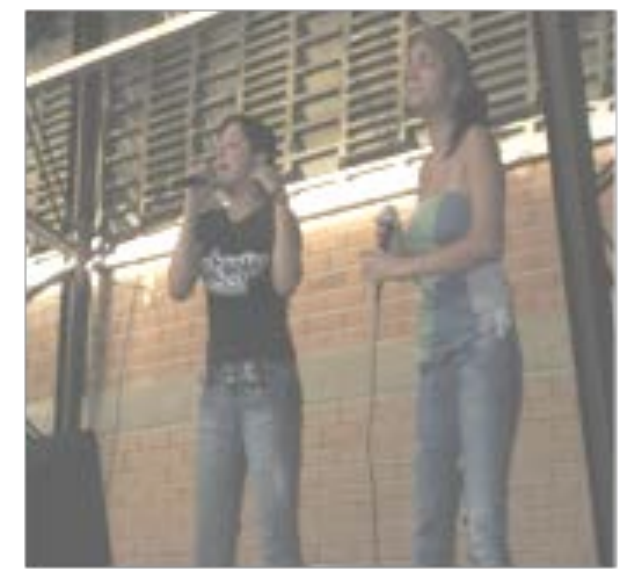

Concierto de hip hop "Tejiendo redes de solidaridad" Universidad de Antioquia (2011)

En las culturas juveniles, la mujer también ha sido poco visible; en el caso del hip hop, ésta ha tenido que buscarse un espacio y poco a poco ir ganando un reconocimiento desde su identidad femenina. La indumentaria de los hoppers (pantalón baggy, camiseta ancha, gorra de visera plana, tenis de skate, muñequeras, pañoletas) ha influido en la posibilidad de que la mujer pueda acceder a esta cultura juvenil, pues este tipo de vestimenta representa una identidad más fuerte, masculina, con la expresión y los movimientos bruscos en el canto y el baile, aunque tampoco la mujer ha sido "bien vista" por dichas características. En la actualidad, la mujer participa de prácticas corporales urbanas de hip hop, específicamente de danza y canto a la par que los hombres. Si bien 
aún son menos las que participan de esta práctica en comparación con los hombres, las chicas han incursionado artísticamente al interior de este género musical y han ganado competencias; y empiezan, al igual que el género masculino, a construir una ideología social de resistencia, de visibilización frente a una sociedad que, al parecer, proporciona pocas oportunidades proporciona a la juventud.

El hombre, a partir de la realización de los murales, evidencia un deseo expreso por un ideal corporal, un cuerpo voluminoso, fuerte, esbelto, longilíneo, súper héroe, que haga de la ciudad y de la escuela un lugar más tranquilo, divertido y acogedor. Ellos, a diferencia de las mujeres, en el mural representan la realidad en la cual se encuentran inmersos: violencia, conflicto social, pobreza, guerra, temor; y esto concuerda con su representación en el etnodrama, el cual es un espejo de su drama juvenil.

\section{CONCLUSIONES}

Se libran procesos de reconocimiento que se producen fuera y dentro de la cultura hopper, evidentes en el adentro y fuera de la cultura escolar. El reconocimiento de una etnocorporalidad juvenil se construye en el referente barrial y social de la Comuna 13 mediante apropiación de la juventud de su vivir y estar en el mundo, su estar en la escuela como espacio de socialización primaria. El hip hop, por sobre el reggaeton, es una elección que refiere el pensamiento masculino y femenino, la representación de la problemática social y la añoranza o posibilidad de dar un giro a la cotidianidad.

La juventud, a través de sus líricas (cantos), producción musical, graffitis y danza, expresa sus sentires, vivencias, pensamientos, ideologías; cultura que la escuela resiste, pero la juventud desterritorializa a través de las prácticas corporales urbanas de danza y tradicionales de fútbol, dándole una significación particular que da cuenta de una constitución identitaria propia.

Existe una diferencia marcada desde el pensamiento femenino y masculino evidenciado en los murales y el etnodrama. En las mujeres prevalece un ideal romántico (constituir una familia nuclear, amar y ser amadas, ser protegidas por su esposo...) pero, en la realidad, vivencian otras situaciones (se muestran como mujeres independientes quienes sacan adelante a sus hijos, que trabajan y tienen el control de su propia vida). Esto implica una diferencia con los hombres, en los que predomina un pensamiento que coincide con su realidad: violencia, guerra y deseos, añoranzas por vivir otro tipo de experiencias y de encontrar en el arte una alternativa de vida (como ellos lo expresan, robándoselos a la guerra).

$\mathrm{Al}$ interior de la cultura hopper se expresa una etnocorporalidad masculina y femenina construida desde los rasgos identitarios masculinizados que luchan con lo femenino; las mujeres, en busca del reconocimiento y aceptación, enmascaran sus rasgos identitarios. La práctica corporal urbana de danza da cuenta de una cultura corporal juvenil cuyos rasgos están manifiestos en la forma de vestir, en su forma de expresarse, en sus movimientos (motricidad), lo cual para las chicas es una oportunidad de reconocimiento, aunque en la práctica del hip hop es también una lucha del afuera (barrial, escolar), donde sus compañeros las aceptan "a regañadientes" y ellas siguen patrones de masculinización que las invisibilizan. El ascenso de lo femenino en la cultura hopper, se puede afirmar, todavía está estigmatizado. 


\section{REFERENCIAS BIBLIOGRÁFICAS}

Agudelo y Fandiño. (2010). Laberinto. "Los sueños pueden hacerse realidad”. La nación subterránea, n.0, 14-15.

Aguirre, A. y Rodríguez, M. (1996). Skins, punkis, okupas y otras tribus urbanas españolas. Anthropologica, n.19.

Aguirre, A. (1995). Etnografía Metodología cualitativa en la investigación sociocultural. México: Alfaomega Marcombo.

Aguirre, S. (1995). Entrevistas y cuestionarios. En A. Aguirre, Etnografía Metodología cualitativa en la investigación sociocultural (pp. 171-180). México: Alfaomega Marcombo.

Barbero, Jesús. (2002). Jóvenes: comunicación e identidad. Pensar Iberoamérica. Revista de Cultura. Consultado en http://www.oei.es/pensariberoamerica/ric00a03.htm [última visita: 29/03/2012].

Barbero, José. (2006). Ficción autobiográfica en torno a la cultura corporal y la vida cotidiana. Educación Física y deporte, vol.25, n.2, 47-63.

Cachorro, G. y Díaz, L. (2004). La mundialización de las prácticas corporales. Trampas de la Comunicación, n. 25, 1-17. Consultado en http://www.revista-artefacto.com.ar/pdf_textos/27. pdf [última visita: 03/02/2012].

Cachorro, G. (2012). Deporte prácticas corporales y subjetividad. Artefacto. Pensamientos sobre la técnica, n. 27 Consultado en http://www.revista-artefacto.com.ar/pdf_textos/27.pdf [última visita: 20/03/2012].

Cachorro, G. (2009). Preguntas para graficar prácticas corporales. En G. Cachorro et al., Educación física: Cultura escolar y cultura universitaria (pp. 95-114). Argentina: Editorial La Plata:

Calvo, C. (2005). Entre la educación corporal caótica y la escolarización corporal ordenada. Revista Iberoamericana de Educación, n. 39, 91-106.

Galvis, N. (2009). Prácticas corporales un despliegue del cuerpo en la tensión de lo formal y lo informal. Educación Física y deporte. Medellín: Funámbulos editores.

Garcés, A. (2007). Juventud, música e identidad. Hip hop en Medellín. En Educación cuerpo y ciudad. El cuerpo en las interacciones e instituciones sociales (pp. 229 - 254). Medellín: Funámbulos Editores.

Garcés, A. (2005). Nos-otros los jóvenes. Polisemias de las culturas y los territorios musicales en Medellín. Medellín: Universidad de Medellín.

Garcés, A. (2002). Ser hombre/ser mujer vidas separadas en Medellín 1900- 1940. Revista Universidad de Medellín, n.74, 142-166.

García, N. (1992). Culturas híbridas. Estrategias para entrar y salir de la modernidad. Buenos Aires: Editorial Sudamericana.

Gardner, H. (1991). La danza. Kinesis. Bogotá: Res. Min. Gobierno, vol.2, n.6. 2113/89.

Giroux, H. (1985). Teorías de la reproducción y la resistencia de la nueva sociología. Cuadernos políticos, n. 44, 36-65.

Hanna, J. (1979). Towards a cross-cultural conceptualization of dance and some correlate considerations. En: J. Blacking\& J. Kealiinohomoku (eds), The Performing Arts. The Hauge: Mouton.

Le Boulch, J. (1997). El movimiento en el desarrollo de la persona. Barcelona: Paidotribo.

Lifar, S. (1968). La danza. París. Tubor. S.A.

Lefebvre, H. (1970). La lógica formal, la lógica dialéctica. España: Siglo veintiuno.

Létourneau, J. (2007). La caja de herramientas del joven investigador. Medellín: La carreta.

Londoño, A. (1995). Baila Colombia. Medellín: Universidad de Antioquía.

Maffesoli, M. (1990). El tiempo de las tribus. Barcelona: Icaria.

Márquez, F. (2008). Deseos \& identidades en disputa Santiago de Chile: 1958 - 2008. Revista chilena de antropología visual, n. 12, 147-170.

Martínez Bonafe, J. (2009). La ciudad en el curriculum y el curriculum en la ciudad. En J. Sacristán, Saberes e incertidumbres sobre el curriculum (pp. 527-547). Madrid: Morata. 
Reguillo, R. (2000). Emergencia de culturas juveniles. Estrategias del desencanto. Bogotá: Editorial Norma.

Rockwell, E. (2009). La experiencia etnográfica. Historia y cultura en los procesos educativos. Buenos Aires: Paidós.

Ruiz, J. (2003). Medellín: Fronteras de discriminación y espacios de guerra. Medellín: Centro de estudios de opinión.

Salerno, D. y Silba, M. (2006). Juventud, identidad y experiencia: las construcciones identitarias urbanas. Question, vol. 1, n. 10. Consultado en: http://perio.unlp.edu.ar/question/ numeros_anteriores/numero_anterior10/nivel2/articulos/informes_investigacion/salernoysilba_1_informes_10oto\%F1o06.htm [última visita: 29/03/2012].

Silva, J. (2002). Juventud y tribus urbanas: en busca de la identidad. Revista Última Década, n.17, 117-130.

Soares, C. (2006). Prácticas corporales: Historias de lo diverso y lo homogéneo. En Cuerpo y cultura: prácticas corporales y diversidad (pp. 9-36). Argentina: Libros del rojas.

Weisz, G. (1994). Posmodernismo, rito y biología. En Cuaderno Iberoamericano de reflexión sobre escenología. Vanguardia, postmodernismo, performance, happening (pp. 93-98). México: XXI. 
